\title{
A ESCOLA E OS SETE SABERES: REFLEXÕES PARA AVANÇOS INOVADORES NO PROCESSO EDUCATIVO
}

\author{
Ricardo Antunes de Sá* \\ Sonia Maria Marchioratto Carneiro*:* \\ Araci Asinelli da Luz***
}

\begin{abstract}
RESUMO
Este artigo objetiva trazer contribuições aos educadores quanto aos processos de ensino e de aprendizagem na escola, com base no pensamento complexo de Edgar Morin e considerando as discussões da Conferência Internacional Os Sete Saberes Necessários para a Educação do Presente, realizada em setembro de 2010, em Fortaleza (CE). É desenvolvida uma análise compreensiva e dialógica sobre os princípios necessários para se efetivar uma educação que possibilite aos educandos refletir e intervir no mundo presente e futuro, sob um outro olhar epistêmico para enfrentar os desafios do pensar e do conhecer hoje necessários, na busca de um novo modo de ser.
\end{abstract}

Palavras-chave: Teoria da complexidade. Educação. Escola.

\section{ABSTRACT \\ THE SCHOOL AND THE SEVEN KNOWLEDGE: REFLECTING ON INNOVATIVE ADVANCES WITHIN SCHOOL EDUCATION}

The article aims at contributing to educators' advancement in teaching and learning school processes, upon Edgar Morin's book "The Seven Necessary Knowledge in Education for the Future" (2003) and discussions held by the International Conference The Seven Necessary Knowledge in Education for the Present, at Fortaleza (CE), September of 2010. There follows a comprehensive and dialogic analysis about some

\footnotetext{
* Pedagogo. Doutor em Educação. Professor Adjunto III. Docente e pesquisador do Programa de Pós-Graduação em Educação, do Setor de Educação na Linha Cultura, Escola e Ensino. Membro do Grupo de Pesquisa Educação, Ambiente e Sociedade, do Setor de Educação da Universidade Federal do Paraná. Endereço: José Rebelato, 240 - Sobrado - 01 - Xaxim - CEP: 81710 010 - Curitiba-PR. Telefone: (41) 31526146. antunesdesa@gmail.com

** Geógrafa. Doutora em Meio Ambiente e Desenvolvimento. Professora Adjunta IV. Professora do Programa de Pós-Graduação em Educação na Linha de Cultura, Escola e Ensino. Membro do Grupo de Pesquisa Educação, Ambiente e Sociedade, do Setor de Educação da Universidade Federal do Paraná. Endereço: Rua Carmelo Rangel, 1260 - CEP: 80440-050 - Curitiba-PR. Telefone: (41) 3342-6681 / (41) 91124514. carneiro.sonmaria@gmail.com

*** Doutora em Educação. Professora Associada. Docente e pesquisadora do Programa de Pós-Graduação em Educação, do Setor de Educação da Universidade Federal do Paraná. Professora do Programa de Pós-Graduação em Educação, na linha de Pesquisa Cognição, Aprendizagem e Desenvolvimento Humano. Membro do Grupo de Pesquisa Educação, Ambiente e Sociedade, do Setor de Educação da Universidade Federal do Paraná. Membro do Conselho e do GT-Educação da SBPC. Endereço: Rua João Luiz Costa, 21 - Jardim Social - CEP 82.530-140 - Curitiba-PR. Telefone: (41) 9162-4503. araciasinelli@hotmail.com
} 
principles in view of an education enabling children and youngsters to be reflective and active in the world. Therefore, an in-the-present and for-the-future school needs another epistemic sight to cope with thinking and knowing challenges in the search of a new quality of well-being.

Keywords: Complexity theory. Education. School.

\section{Introdução}

Este texto foca a escola contemporânea a partir da obra de Edgar Morin (2003) Os Sete Saberes Necessários à Educação do Futuro e da Conferência Internacional Os Sete Saberes Necessários para a Educação do Presente, realizada em setembro de 2010, em Fortaleza (CE). A Conferência, com participação de diversos grupos de estudos e pesquisas, de professores da Educação Básica e dos representantes de Secretarias de Educação Estaduais e Municipais de todo o Brasil, buscou valorizar os pressupostos epistemológicos e metodológicos da Teoria da Complexidade - segundo a sistematização de Edgar Morin - tendo em vista as experiências e discussões de sua incorporação à educação. Esse evento colocou em pauta preocupações recentes da educação brasileira, assim como de outros países, trazendo ao debate acadêmico-científico instigantes e inquietantes contribuições para a pesquisa e a formação de educadores e, a mais, abrindo perspectivas de reflexão sobre paradigmas emergentes da ciência e suas implicações na inovação das práticas educativas, presentes e futuras.

A Conferência discutiu e clarificou pontos e nós da rede de pesquisadores e estudiosos que vêm tematizando o pensamento complexo, a fim de religarem os saberes dispersos das áreas do conhecimento, em vista de novas conexões entre as ciências da natureza e as sociais. Nessa perspectiva, entram em jogo implicações da conhecida máxima pascalina, na proposição de Morin (2005, p. 103): "Considero impossível conhecer as partes enquanto partes sem conhecer o todo, mas não considero menos impossível a possibilidade de conhecer o todo sem conhecer singularmente as partes." O evento foi uma iniciativa político-pedagógica que objetivou " [...] iniciar um profícuo diálogo entre escolas e universidades, para intercâmbio de saberes e de práticas pedagógicas capazes de iluminar novos cursos de formação docente, a partir da complexidade" (CONFERÊNCIA..., 2010, p. 10).

$\mathrm{O}$ artigo foi desenvolvido como um diálogo reflexivo sobre a Teoria da Complexidade e os desafios da escola contemporânea, com o especial objetivo de trazer contribuições aos educadores quanto aos processos de se ensinar e aprender na escola, sob uma perspectiva epistemológica com base no pensamento complexo de Edgar Morin e tendo como referência os eixos temáticos da sua obra-acima citada - e textos publicados nos Anais da Conferência. Nesse rumo, a escola precisa rever suas práticas sociopedagógicas para que as novas gerações aprendam a pensar, compreender, contextualizar e globalizar os saberes que emergem necessários à multidimensionalidade da vida-hoje. Conforme Antônio (2009), a educação necessita ser repensada sob uma nova epistemologia. Assim, um dos grandes desafios das práticas pedagógicas, atuais e do futuro, é transitar unitariamente pela diversidade do conhecimento, rompendo as fronteiras disciplinaristas rígidas - e isto enquanto uma questão filosófica central da Educação. Sobre isso, Santos (2008, p. 81) argumenta que "A complexidade [constitui] um corpo teórico que possibilita o resgate do elo perdido, o sentido do conhecimento para a vida".

\section{As cegueiras do conhecimento e a es- cola}

A assertiva em foco remete à compreensão de que o conhecimento elaborado, notadamente o científico, é uma interpretação da realidade e, estendido à escola, privilegia o real pedagógico. Essa interpretação comporta erros e desvios, perturbações e ruídos que interferem na percepção intelectiva do educando, do professor e ou do pesquisador. As interpretações, por mais racionais e lógicas que possam parecer, incorporam sempre interferências subjetivas, emocionais e culturais, 
as quais são intrínsecas ao sujeito que opera a elaboração do conhecimento.

É preciso considerar que - na escola, de maneira específica, e na vida de maneira geral - o desenvolvimento das capacidades cognitivas implica a inseparabilidade da paixão, da afetividade, da curiosidade e da imaginação. No entanto, essas dimensões só se tornam frutíferas para a emancipação e autonomia intelectual do indivíduo quando mantêm um equilíbrio dinâmico, o que significa que "A afetividade pode asfixiar o conhecimento, mas pode fortalecê-lo [...], a faculdade de raciocinar pode ser diminuída, ou mesmo destruída, pelo déficit de emoção; o enfraquecimento da capacidade de reagir emocionalmente pode mesmo estar na raiz de comportamentos irracionais" (MORIN, 2003, p. 20).

A teorização sobre a escola, a organização das ações pedagógicas e a prática docente necessitam integrar um permanente diálogo com a prática in $a c t u$. Tal diálogo não é aleatório nem espontaneísta, mas referenciado a fatos e fenômenos pensados reflexivamente na construção de objetivações mediadoras entre os processos de compreensão, decisões e ações nos contextos culturais, para além de sistemas de ideias enquanto certeza de conhecimento. Daí que, as grandes interrogações sobre o conhecer pedagógico comportam "[...] desenvolver nova geração de teorias abertas, racionais, críticas, reflexivas, auto-críticas, aptas a se auto-reformar." (MORIN, 2003, p. 32).O fenômeno mais distorcido que a racionalização pragmática pode trazer ao trato com o conhecimento científico em relação à educação é a fragmentação do conhecimento - sua reificação em pressupostos que simulam a explicação da complexidade do real e não dialetizam nem dialogam com a teia multidimensional da sociedade, do humano, da vida.

Torna-se importante a escola contemporânea assumir que a racionalidade, e não a racionalização, é uma prerrogativa do conhecimento científico e da ação educativa. Uma postura de permanente diálogo epistêmico abre caminho a todos os professores e pedagogos que lidam com o conhecimento, para o avanço da educação. A racionalidade é saudável no diálogo com o real pedagógico em busca da compreensão e da elaboração de estratégias de intervenção para aprimorar, transformar e melhorar o espaço da ação educativa, a fim de intervir para humanizar, para criar uma ambiência cooperativa, colaborativa e sinceramente democrática: "Opera $o$ ir e vir incessante entre a instância lógica e a instância empírica; é o fruto do debate argumentado das ideias, e não a propriedade de um sistema de ideias." (MORIN, 2003, p. 23).

A racionalização, em suas particularidades, pode causar distorção do exercício da racionalidade, com descambo ao autoritarismo teórico, para a visão unidimensional da realidade escolar que, no dis curso, traveste-se de democrática e dialógica. Distorções da racionalização estão frequentemente presentes na área de formação de professores e estendem-se mecanicamente à prática escolar, deixando os educadores imobilizados para uma coerente reflexão crítica sobre o fenômeno educativo. Racionalizações pedagógicas acríticas cegam o diálogo e a produção de um conhecimento válido frente às complexas tessituras da organização escolar.

Os fenômenos que se manifestam no âmbito da escola, sejam de ensino e de aprendizagem, de gestão, de organização e planejamento, de relações profissionais ou pessoais, comportam, por parte dos profissionais da educação, uma posição epistemológica, profissional e política. A dimensão epistemológica compreende a racionalidade científica, o método de investigação e a busca de respostas que possibilitem intervenções pertinentes e qualificadas na organização escolar, com o objetivo de que esta instituição cumpra seu papel formativo social, científico, político e cultural. A dimensão profissional articula-se às demais dimensões, na medida em que professores, pedagogos e técnicos têm claro seu papel e suas responsabilidades perante a natureza e a especificidade da escola. Esta dimensão estriba-se não apenas na básica questão salarial, mas evoca pertinências teórico-metodológicas no trato com a questão pedagógica. A dimensão política, por sua vez, é o compromisso com a formação do cidadão, sob os princípios da ação intersubjetiva no diálogo entre os diferentes e os diversos e do respeito à cooperação, à colaboração e à solidariedade.

Morin (2003) define muito bem o trato do conhecimento lúcido e pertinente, enfocando que o saber necessário, para o presente e futuro, demanda lides educacionais que incorporem o racional e o 
emocional, pois o conhecimento científico exige observação e auto-observação, crítica e autocrítica nos processos reflexivos e de intervenção.

Os textos divulgados pela Conferência em foco (VIEIRA et al., 2010a; VIEIRA et al., 2010b; SANTOS, 2008; PETRAGLIA, 2000) destacam a necessidade de o educador buscar sentidos e significados com os educandos, a partir de atividades de observação e diálogo crítico-reflexivo sobre a multidimensionalidade do objeto em estudo, como maneira de se perceber as diferenças e as contradições existentes no mundo. Nesse contexto, surgem possibilidades de diálogo sobre a questão da verdade absoluta, do erro, da ilusão e da incerteza na construção dos conhecimentos, dada a subjetividade individual; esta, sempre vivenciada em diferenciações culturais, leva a que um objeto possa ser visto e olhado de várias maneiras, desde a percepção sensorial e a interpretação do vivido, passando por desejos, afetos e temores. Nessa linha de reflexão, os educandos poderão compreender a provisoriedade dos conhecimentos, alcançando entender que nem tudo que se sabe hoje será válido amanhã; além de visualizarem o erro não como oposição ao conhecimento - o que é normalmente entendido na cultura escolar -, mas sim como critério de avanço da ciência, em perspectiva de curiosidade epistemológica (FREIRE, 1996). Assim, quando o educando se percebe "[...] agente do processo de construção do conhecimento, em que o erro se torna parte integrante desse processo, sua curiosidade torna-se mais viva, dinâmica e contributiva." (VIEIRA et al., 2010b, p. 4).

Portanto, a consideração das cegueiras do conhecimento - a serem trabalhadas na escola - possibilita um dos saberes fundamentais para que os educandos passem a ver o mundo numa perspectiva contextual e flexível, em contraposição a uma visão linear e reducionista.

Sob essa ótica, uma reforma de pensamento pedagógico - de natureza paradigmática e não programática, segundo Morin (2003) - faz-se necessária, pondo como questão fundamental da educação os pressupostos filosóficos para tratar e organizar o conhecimento. Isso exige dos educadores processos de auto-organização frente ao imprevisível e, consequentemente, capacidade de gerar mudanças e transformações na maneira de perceber a realidade educacional e de construir o conhecimento.

\section{Os princípios do conhecimento e a es- cola}

Organizar o conhecimento é uma aptidão necessária para o cidadão de hoje, no acesso às informações e no saber como articulá-las, de modo a reconhecer e conhecer questões do mundo contemporâneo. Assim, torna-se essencial saber organizar os conhecimentos no sentido de aprender a aprender (MORIN, 2013). Organizar os conhecimentos não se reduz, entretanto, à classificações e categorizações externas, puramente conceituais, mas em uma apropriação hermenêutica de seus sentidos que possibilitem um estar-no-mundo mais autônomo e consciente.

O conhecimento chamado "pertinente" relaciona-se à consideração da complexidade das diversas dimensões que constituem a realidade - física, biológica, histórica, econômica, cultural, política etc. Para tanto, é necessário superar o conhecimento disjuntivo, que impede a apreensão e compreensão de realidades complexas, em suas múltiplas interconexões e relações.

Nesse sentido, é importante que os educadores, comprometidos com as novas gerações, desenvolvam um ensino que possibilite aos educandos pensar a realidade de forma complexa, em vista da sua formação como cidadãos éticos. Sob essa ótica, urge - na interação de interpretar e intervir - que a escola reelabore categorias para o enfrentamento dos desafios da atual sociedade globalizada, altamente científica e tecnológica. Com efeito, um conhecimento pertinente, do e no mundo, requer a evidenciação de eventos, fatos, fenômenos, dados, experiências nas suas perspectivas contextuais, globais, multidimensionais e complexas. Cabe, pois, designar esses aspectos de inteligibilidade conceitual como categorias.

A categoria contexto situa os dados e as informações, denotando significados, sentidos, densidade etc., possibilitando a compreensão da tessitura do objeto estudado; porquanto, o educando só apreende os conhecimentos quando são contextualizados sob os aspectos global, geográfico e histórico, pois conhecer um dado isolado não lhe permite alcançar o entendimento do todo. 
Por sua parte, a categoria global vai além do contexto, referindo-se ao conjunto das partes ligadas a ele, de modo inter-retroativo ou organizacional; refere-se, portanto, às relações entre as partes e destas com o todo e vice-versa. O todo não é a soma das partes. As partes possuem características e especificidades que, na sua dinâmica inter-relacional, auto-eco-organizativa, formam o todo; e este tem qualidades que não são encontradas nas partes, se estas estiverem separadas umas das outras. Por isso, é preciso ter conhecimento do todo para entender as partes.

A categoria multidimensionalidade relaciona-se aos diversos aspectos constitutivos do indivíduo e às várias instâncias da sociedade (econômica, histórica, política, jurídica, social etc.), interconectadas em configuração hologramática, isto é, sob o aspecto da presença do todo nas partes. $\mathrm{O}$ conhecimento pertinente, portanto, incorpora essa característica multidimensional da realidade, pois cada dimensão está inter-relacionada com a outra, de forma inter-retroativa permanente, modificando-se constantemente.

Já a categoria complexo diz respeito às interligações presentes na natureza e na sociedade, urdidas pelas inter-retro-eco-ações; é a junção entre unidade e multiplicidade - o que foi tecido junto. Portanto, "[...] há um tecido interdependente, interativo e inter-retroativo entre o objeto de conhecimento e seu contexto, as partes e o todo, o todo e as partes, as partes entre si” (MORIN, 2003, p. 38).

Nessa perspectiva, a educação tem por finalidade promover o desenvolvimento da inteligência dos educandos, para se tornarem aptos a raciocinar sobre os objetos de estudo com base nas categorias de contexto, do complexo e do multidimensional dentro da concepção global; pois é dessa maneira que aprenderão a (re) ligar os saberes e ter condições de compreender as questões sobre o mundo e de intervir nele, criteriosa e responsavelmente, na prevenção e solução de problemas. Observa-se que um conhecimento pertinente não se caracteriza pela quantidade de informações, mas pela sua organização simultaneamente analítica e sintética das partes religadas ao todo e do todo religado às partes. É dessa maneira que o educando terá condições de apreender a complexidade, as conexões ocultas e intrínsecas a toda a realidade. Tal encaminhamento pedagógico opõe-se ao conhecimento disjunto, em favor da articulação entre as diversas áreas de ensino, a partir de uma relação dialógica, via um planejamento aberto, flexível, que possibilite um trabalho escolar problematizador (VIEIRA et al., 2010a; VIEIRA et al., 2010b; SANTOS, 2008; PETRAGLIA, 2000; MARTINAZZO, 2010a). Nessa linha destaca-se a valorização da transversalidade curricular e de projetos educacionais inter e transdisciplinares, que favoreçam a construção conjunta e colaborativa do conhecimento escolar. Para Morin (2003), esse é um dos desafios da educação do presente, na medida em que há, de um lado, uma inadequação profunda entre os saberes divididos e, de outro, as realidades ou problemas multidisciplinares, multidimensionais, globais e planetários. Assim, a inter-relação das áreas de ensino torna-se uma exigência cognitiva-e-pedagogicamente natural para proporcionar a compreensão da realidade complexa pelos educandos e, com isso, serem capazes de enfrentar e resolver os problemas emergentes, na linha da cidadania planetária, portanto, local-global. Além de tudo, de acordo com Santos (2008, p. 76), “[...] trabalhar a educação com tal visão supera a mesmice do padrão educativo, encanta o aprender e resgata o prazer de aventurar-se no mundo das ideias".

Ao ter a Escola a finalidade político-pedagógica de formar cidadãos, incumbe-lhe assumir que eles não existem sem conhecimentos de problematização, que não se constituem sem a capacidade intelectual de pensar e de saber pensar:

A educação deve favorecer a aptidão natural da mente em formular e resolver problemas essenciais e, de forma correlata, estimular o uso total da inteligência geral. Esse uso total pede o livre exercício da curiosidade, a faculdade mais expandida e a mais viva durante a infância e a adolescência, que com freqüência a instrução extingue e que, ao contrário, se trata de estimular ou, caso esteja adormecida, de despertar. (MORIN, 2003, p. 39).

\section{Ensinar a condição humana na escola}

Ensinar a condição humana numa perspectiva complexa é permitir o desvendamento de seus diversos enraizamentos: cósmico, físico, terrestre e do próprio ser humano. Morin (2003) traça uma 
via de interligação e interdependência que revela, primeiro, nossa dimensão cósmica. Somos cósmicos porque as partículas de nosso organismo, da vida na Terra, são provenientes da formação inicial do Universo, em constante auto-organização. A condição física teve origem pela termodinâmica sobre a Terra, ou seja, por meio das condições energéticas provenientes do Sol; já a condição terrestre relaciona-se à biosfera terrestre - nosso Planeta Terra - quanto ao seu complexo biofísico. E o humano é resultado de uma evolução de milhões de anos que se foram sucedendo, até chegar à espécie Homo Sapiens, diferenciada das espécies anteriores pela sua complexificação psicossocial e cultural, especialmente pela linguagem. Na realidade, o conceito de homem implica duplo princípio: um biofísico e, o outro, psico-sociocultural. Não há como conceber o ser humano sem essa dupla raiz de origens: o humano é ao mesmo tempo um ser biológico e cultural, que traz em si uma unidualidade. Assim, entender o humano é compreender sua unidade na diversidade e vice-versa, o que traduz uma antropologia complexa (MORIN, 2003, 2013). A escola, ao trabalhar esse saber, estará refletindo sobre a complexidade humana - a sua unidade e diversidade quanto aos constituintes biológicos, psicológicos e socioculturais. Tal reflexão implica a discussão triádica de indivíduo, sociedade e espécie humana, em que cada sujeito é produto e produtor da espécie e, no seu conjunto, forma a sociedade, que produz cultura e é por ela produzida.

Essas perspectivas possibilitam a compreensão da relação entre indivíduo e sociedade e, nesse sentido, conduzem à tomada de conhecimento e conscientização dos educandos sobre a condição humana e da diversidade dos indivíduos, dos povos e das culturas - "[...] sobre nosso enraizamento como cidadãos da Terra [...]." (MORIN, 2003, p. 61). Assim, a importância da escola tratar a condição humana nos diferentes conteúdos curriculares, entre os quais as questões socioambientais - tão presentes nos dias atuais e que afetam a fragilidade biossocial dos habitats humanos. Decorre daí a noção de interdependência, necessidade do cuidado por relações saudáveis entre os seres humanos e desses com o meio natural, em vista do trato das realidades de vida e desenvolvimento de condições desejáveis. Além disso, vale ressaltar a importância desse saber escolar, para os educadores poderem entender melhor seus educandos, na medida em que os entendam como seres biológicos, psíquicos, afetivos, sociais e intuitivos e, sob essa ótica, reconhecendo suas subjetividades e problemas pessoais no ato educativo (VIEIRA et al., 2010a; VIEIRA et al., 2010b; SANTOS, 2008; PETRAGLIA, 2000).

\section{Ensinar a identidade terrestre na escola}

Conceber a identidade terrena implica refletir sobre os problemas do nosso mundo e as condições que foram produzidas pelo homem ao longo dos tempos: a era planetária. Nesse sentido, é importante pensar as condições de vida que os seres humanos vêm produzindo, especialmente a partir do processo de globalização e mundialização, que criou problemas vitais para a humanidade - a intersolidariedade de problemas, antagonismos, crises e processos vários, aleatórios, senão descontrolados. A globalização vem-se constituindo, notadamente desde o século XV, pela dominação do ocidente europeu que, ao mesmo tempo, produziu sérios problemas civilizatórios - destruição, escravidão e exploração, especialmente das Américas e da África-e desencadeou planetariamente a expansão do comércio e o encurtamento das distâncias entre os povos. A globalização econômica pós-industrial, capitaneada pelas forças produtivas do capitalismo, que no século XX se generaliza como economia de caráter neoliberal mundializada, cada vez mais se faz interdependente pelo desenvolvimento das telecomunicações e informática (MORIN, 2003).

A mundialização, na fase atual, tornou o Planeta um todo, ou seja, cada parte do mundo faz parte do mundo, e o mundo em sua totalidade está cada vez mais presente em cada uma de suas partes isso se verifica não apenas para as nações e povos, mas também para os indivíduos. Tal processo de mundialização caracteriza-se por uma unificação conflituosa, permeada por interesses políticos e econômicos que impõem uma globalização cultural, afetando os modos de pensar e viver das sociedades diversas do mundo, gerando conflitos socioculturais; e além do mais, o mercado mundial dominador visa essencialmente ao lucro e não à qualidade de vida planetária. Como escreve Morin (2003, p. 75), “A união planetária é a exigência 
racional mínima de um mundo encolhido e interdependente. Tal união pede a consciência e um sentimento de pertencimento mútuo à Terra, considerada como [...] pátria". Para tanto, é necessário propiciar uma educação escolar cidadã e planetária que possibilite o desenvolvimento nos educandos da consciência ecológica e sociocultural, relacionada à conservação dos ambientes de vida, e uma aceitação da diversidade cultural, reconhecendo-se a unidade na diversidade. Com isso, reforça-se a importância da coexistência de modos de vida ante a intensificação de movimentos de pessoas e grupos mediante as tecnologias de comunicação e transporte.

Portanto, pensar uma identidade terrena significa que os seres humanos adotem posturas de responsabilidade para com as diferentes realidades socioambientais. $\mathrm{Na}$ escola, essa premissa deve perpassar todos os conteúdos curriculares, ensejando uma prática educativa articuladora do conhecimento, sob uma orientação ético-social. Para tanto, é necessário o educando desenvolver uma autopercepção de pertencimento ao Mundo-Terra e ao Universo, entendendo que somos enquanto existentes, ao mesmo tempo, a unidade e a diversidade juntas: unidade como um Planeta, em suas características cósmicas e, ao mesmo tempo, mais um e mais outros no todo do universo. Também se faz ideativamente indispensável ao educando compreender que nosso Planeta possui características diferentes em cada ponto de sua geografia - e que devem ser respeitadas. A responsabilidade da educação escolar, portanto, implica ajudar os educandos a entenderem que o Planeta Terra é único e deve ser conservado enquanto lugar de habitar e conviver, para as gerações presentes e as futuras (VIEIRA et al., 2010a; VIEIRA et al., 2010b; SANTOS, 2008; PETRAGLIA, 2000). E aí está uma nova postura educacional, emergente e urgente, para a busca de uma identidade terrena, conforme alude Morin (2003, p. 78, grifo do autor):

O duplo imperativo antropológico impõe-se: salvar a unidade humana e salvar a diversidade humana. Desenvolver nossas identidades a um só tempo concêntricas e plurais: a de nossa etnia, a de nossa pátria, a de nossa comunidade de civilização, enfim, a de cidadãos terrestres. [...] Civilizar e solidarizar a Terra, transformar a espécie humana em verda- deira humanidade torna-se o objetivo fundamental e global de toda educação que aspira não apenas ao progresso, mas à sobrevida da humanidade. [...] A educação do futuro [e do presente deve] ensinar a ética da compreensão planetária.

\section{Enfrentar as incertezas na escola}

É uma premissa que diferencia a educação-hoje da tradicional, que ensinava a pensar os fenômenos sob um foco de regularidade; um bom planejamento, por exemplo, poderia ordenar tudo, organizar os processos de forma que funcionassem como um relógio. Nos dias atuais, em vista da velocidade acelerada das dinâmicas complexas e aleatórias da era planetária, é necessário levar em consideração o princípio da incerteza; isto é, entender que o universo é jogo e risco da dialógica entre a ordem, a desordem e a organização. E sob essa condição, está a realidade humana - seja a história da humanidade, a história individual, a história da escola. Assim, a educação do presente para o futuro precisa defrontar-se com as incertezas do conhecimento, pois, segundo Morin (2003, p. 84-85), existe:

[...] Um princípio de incerteza cérebro-mental, que decorre do processo de tradução/reconstrução próprio a todo conhecimento. [...] Um princípio de incerteza lógica: como dizia Pascal muito claramente, 'Nem a contradição é sinal de falsidade, nem a não contradição é sinal de verdade.' [...] Um princípio da incerteza racional, já que a racionalidade, se não mantém autocrítica vigilante, cai na racionalização. [...] Um princípio da incerteza psicológica: existe a impossibilidade de ser totalmente consciente do que se passa na maquinaria de nossa mente, que conserva sempre algo de fundamentalmente inconsciente. Existe, portanto, a dificuldade do autoexame crítico, para o qual nossa sinceridade não é garantia de certeza, e existem limites para qualquer autoconhecimento.

Diante das incertezas inerentes à condição humana, a realidade não é tão satisfatoriamente legível quanto suposto por imediatismos pragmáticos. Ideias e teorias que pretendam traduzir a realidade via esquemas simplistas podem sempre equivocar-se. Nesse rumo, alerta Morin (2003, p. 85): "Por isso, importa não ser realista no sentido trivial (adaptar-se ao imediato), nem irrealista no 
sentido trivial (subtrair-se às limitações da realidade); importa ser realista no sentido complexo: compreender a incerteza do real, saber que há algo possível ainda invisível no real".

Portanto, o conhecimento é passível de ilusão e de erro, e nas certezas doutrinárias intolerantes encontram-se as piores ilusões; ao contrário, numa consciência do caráter incerto das cognições está a oportunidade de se chegar ao conhecimento pertinente, o que requer verificações e convergências de indícios. Para enfrentar a incerteza é importante levar em consideração duas questões: o desafio e a estratégia. $\mathrm{O}$ desafio relaciona-se à consciência da aposta (hipótese), partir da qual entra em cena a estratégia, como momento de se elaborar cenários de ação e de examinar as certezas e as incertezas de uma determinada situação - as probabilidades e improbabilidades. É importante considerar-se a prudência e a audácia no diálogo entre fins e meios, tendo como base o contexto sob a análise. Além disso, na estratégia pesam as complexidades inerentes às próprias finalidades previstas, máxime, no caso de a estratégia comportar modificações, em vista de imprevistos, de informações novas etc. Nesse sentido, toda oportunidade envolve risco e vice-versa, de modo que ante a incerteza, o inesperado e o improvável, tudo é possível. Aqui vale ressaltar a ideia de "ecologia da ação", de Morin (2003), isto é, considerar a complexidade supondo o aleatório, a iniciativa, a decisão, o imprevisto e a consciência dos desvios e das transformações. Isso, conforme Santos (2008), equivale a um jogo de ações e inter-relações, significando que o conhecimento é dinâmico, embora também possa ser submetido ao "fenômeno do reducionismo", seguindo caminhos inesperados, nem sempre coincidentes com as expectativas iniciais.

Com efeito, a incerteza é um saber a ser ensinado na escola; o aluno passa a entender que todo conhecimento - de senso comum ou científico -, todo pensamento, planejamento e organização de qualquer atividade raciocinada é permeado pela incerteza e, por isso, passível de desconstrução e reorganização. Essa visão de mundo permite aos educandos entenderem que o futuro é aberto e imprevisível, remetendo-os à incerteza histórica e a um devir problematizador e, com isso, capacitando-os para uma relação mais amadurecida, prudente e consciente com o real e suas injunções circunstanciais (VIEIRA et al.,2010a; VIEIRA et al., 2010b; SANTOS, 2008; PETRAGLIA, 2000). $\mathrm{O}$ entendimento de incerteza histórica pode ser referendado por uma colocação de Petraglia (2000, p. 13), ao lembrar que a "[...] base da epistemologia da complexidade advém de três teorias surgidas na década de 1940: a teoria da informação, a cibernética e a teoria dos sistemas, cujos impactos e aplicações práticas, no entanto, só se manifestariam mais tarde, nas décadas de 1960, 1970 e 1980", evidenciando a dinâmica de mudanças, de transformações epistemológicas da própria ciência. Em suma, a velocidade das informações e as dinâmicas complexas do mundo atual, marcado por profunda crise de desacertos humanos (guerras, massacres, desprezos e ódios interétnicos) e desequilíbrios ecológicos (desastres ambientais e problemas socioambientais), levam a humanidade a desafios complexos, não facilmente legíveis e que, por isso, demandam das escolas uma nova orientação sociopedagógica para empoderar os educandos a desenvolverem análises interpretativas criteriosas, sob a luz dos saberes em foco.

\section{Ensinar a compreensão na escola}

A compreensão relaciona-se a dois sentidos: um intelectual ou objetivo e o outro, intersubjetivo. O primeiro implica apreender em conjunto o texto e seu contexto, o todo e as partes, o múltiplo e o uno. Esse sentido intelectual da compreensão passa pela racionalidade explicativa; já o segundo sentido da compreensão vai além da dimensão intelectual, racional, analítica ou explicativa: comporta a percepção do outro, como sujeito que não é apenas percebido quantitativa e objetivamente, mas implicando um processo de intersubjetividade - de empatia, de identificação e de heteroprojeção. Sob esse foco, a compreensão é sentimento de abertura e de solidariedade, pelo qual o papel da escola está no "Ensinar a compreensão entre as pessoas como condição e garantia da solidariedade intelectual e moral da humanidade" (MORIN, 2003, p. 93). No entanto, é preciso ter-se presente que a compreensão envolve uma série de obstáculos geradores de mal-entendidos ou não-entendidos, pela polissemia de um termo, pela ignorância de costumes culturais 
e, nesse contexto, pelas dificuldades de abertura subjetivo-social a uma outra visão de mundo.

A vivência da atitude compreensiva é a arte de viver e do bem-pensar, a qual deve ser ensinada às novas gerações: aprender a pensar em conjunto, envolvendo-se com o texto e o contexto, o ser e sua realidade ambiente, o local e o global, o multidimensional, enfim, o complexo. E nesse sentido, pensar bem é compreender objetiva e subjetivamente as circunstâncias da vida, evitando-se o pensamento redutor, fragmentador e empobrecedor, seja de um fato, de um evento, de um acontecimento, de um sujeito etc. - pelo contrário, há que se prover e promover o aprendizado sobre do bem-conviver, pois nessa linha estaremos caminhando para mais humanização das relações humanas.

Nesse âmbito, ressalta-se a importância desse saber - ensinar a compreensão - quanto à relativização do que seja o verdadeiro em cada área do conhecimento, requerendo-se do currículo escolar a abertura das fronteiras disciplinares, a fim de que os educandos compreendam o que cada olhar sobre um mesmo fenômeno apreende, sistematiza e elabora. Porquanto, urge mais e mais, nos espaços escolares, diálogos de conscientização sobre a solidariedade intersubjetiva em vista da formação de educandos que saibam conviver com as diferenças, em suas diversas dimensões. Há necessidade da criação de um clima agradável e confiante nas escolas, por meio da escuta sensível e de relações de alteridade, na linha do respeito, da justiça e da dignidade - pilares da ética da convivência saudável (VIEIRA et al., 2010a; VIEIRA et al., 2010b; LIRA et al., 2010; SANTOS, 2008; PETRAGLIA, 2000).

A escola do futuro, mas já como escola do hoje e do agora, não pode prescindir de ensinar e viver a compreensão, não só no que se relaciona ao pensamento complexo, mas enquanto demanda a autocrítica de nossas falhas, beneficia a compreensão dos outros, desfaz a posição de juiz e fomenta a prática da tolerância. Essa visão converge com o pensamento de Freire (2004, p. 24, grifo do autor):

Falo da tolerância como virtude da convivência humana. Falo, por isso mesmo, da qualidade básica a ser forjada por nós e aprendida pela assunção de sua significação ética - a qualidade de conviver com o diferente. Com o diferente, não com o inferior [...]. Na tolerância virtuosa não há lugar para discursos ideológicos, explícitos ou ocultos, de sujeitos que, julgando-se superiores aos outros, lhes deixam claro ou insinuam o favor que lhes fazem por tolerá-los.

O desenvolvimento da Educação, sob essa perspectiva, está no caminho de uma educação para a cidadania planetária, em vista de sociedades democráticas abertas ao mundo. Com efeito, a escola tem um grande desafio hodierno, que é humanizar o homem sob a ética da solidariedade, a partir "[...] da reforma planetária das mentalidades [...]” (MORIN, 2003, p. 104).

\section{Ética do gênero humano na escola}

O sétimo saber compreende o gênero humano, a partir da tríade inseparável: indivíduo, sociedade e espécie, pois cada sujeito é coprodutor do outro: o indivíduo pertencente à espécie humana, na dinâmica interacional com outros indivíduos, produz a sociedade e esta retroage sobre os indivíduos. Para conviver com o outro, é preciso reconhecê-lo como ser humano, em condições de igualdade democrática. O sentimento democrático é um valor fundamental no processo educativo, na medida em que favorece a relação respeitosa entre indivíduo e sociedade - entendendo cada pessoa como cidadão, sujeito responsável e detentor de direitos. Nesse contexto está o respeito à diversidade sociocultural, o que exige busca de consenso nos conflitos mediante o diálogo, para salvaguardar a vida democrática.

O empenho pela vida democrática deve ser um dos pilares do "novo" homem. É uma utopia permanente que impedirá as aventuras autoritárias e totalitárias, as quais impõem aos indivíduos mecanismos coercitivos, com perda da liberdade. A educação cidadã planetária tem, por isso, como princípio básico o desenvolvimento do senso democrático, que supõe valores de responsabilidade e solidariedade com a coletividade - a comunidade local e planetária. É nessa orientação pedagógica que são dadas aos educandos condições de se apreenderem como seres interdependentes para a preservação de si mesmos, da vida, do outro e do Planeta (LIRA et al., 2010). Para tanto, torna-se necessária a reforma da escola, tanto sob o aspecto do conhecimento quanto da formação afetivo- 
-atitudinal. Por conseguinte, faz-se imperativa, hoje, uma Educação que saiba lidar com a ciência, com a técnica e com a ideologia, elucidando aos educandos os fenômenos complexos da realidade e auxiliando-os a intervir no mundo de maneira a melhorar as condições de vida nos ambientes locais e globais.

Assumir sociopedagogicamente a ética do gênero humano é conceber a escola como espaço e lugar de direitos humanos, onde a ética do conhecimento e a ética da responsabilidade não são soluções e sim, caminhos. Nesse sentido, escola como espaço de emancipação dos educandos é o lugar de diálogo e reciprocidade da presença. Freire (1996, p. 33, grifo do autor), sobre a ética do gênero humano, expressa:

Mulheres e homens, seres histórico-sociais, nos tornamos capazes de comparar, de valorar, de intervir, de escolher, de decidir, de romper, por tudo isso nos fizemos seres éticos. Só somos porque estamos sendo. Estar sendo é a condição, entre nós, para ser. Não é possível pensar os seres humanos longe, sequer da ética, quanto mais fora dela. [...] é uma transgressão. Esse saber de referência, aos educadores, pressupõe uma educação integral em prol das grandes mudanças ansiadas pela humanidade: justiça social, igualdade entre os sexos, eliminação do racismo, tolerância religiosa, respeito às minorias, educação universal, equilíbrio ecológico e liberdade política, no contexto de uma desejável e possível sustentabilidade planetária.

\section{Considerações Finais}

As reflexões, em pauta, abrem motivações para uma reforma da escola, tanto sob o aspecto dos conteúdos de conhecimento, quanto da formação afetivo-atitudinal dos educandos. Aos educadores, sempre são bem-vindas perspectivas de uma educação que saiba lidar com a ciência, com a técnica e com a ideologia, elucidando os fenômenos complexos da realidade e preparando os cidadãos-em-formação a intervir pela melhoraria das condições de vida no mundo local-global. As contribuições de Morin (2003) e da Conferência focada apontam desafiadoras inovações de condutas cognitivas e pedagógicas a serem vividas na escola hodierna, enquanto espaço e lugar de aprender, desenvolver e exercitar a humanização dos educandos. A escola é um espaço privilegiado na vivência de interações complexas que aproximam e unem as diversidades, as diferenças dos sujeitos, num movimento dialógico que contempla complementaridades, antagonismos e tensões. É o espaço e lugar onde os educadores dialogam uns com os outros - seus pares e os educandos - numa relação de convivência, de acolhimento e de compreensão. Nesse sentido, é falsa qualquer dicotomia entre professor e educando, pois, segundo Freire (1996, p. 21), “[...] não há docência sem discência [...]".

A escola precisa olhar para os novos desafios do pensamento e do conhecimento humano; precisa se transformar de modo a ser capaz de construir conhecimentos em que docentes e educandos aprendam a se situar e compreender no lugar onde convivem e atuam, desvelando o processo histórico de ser humanidade, desde os primórdios até a atual era planetária, destacando exemplos solidários, porém, sem ocultar a opressão e a dominação (MARTINAZZO, 2010b) - e, nesse sentido, denunciando e repudiando males que poderiam e ser evitados ou, pelo menos, minimizados.

Os sete saberes, necessários para a educação do-presente-e-futuro, dão ensejo ao sonho e fundam a realidade do (re)encontro de educadores e educandos com dimensões do pensar e fazer que valorizem uma racionalidade humanamente compromissada com a felicidade e a identidade terrena e cósmica, numa vinculação - tão construída quanto espontânea - à Natureza, à História e à Cultura.

\section{REFERÊNCIAS}

ANTÔNIO, Severino. Uma nova escuta poética da educação e do conhecimento: diálogos com Prigogine, Morin e outras vozes. São Paulo: Paulus, 2009.

CONFERÊNCIA INTERNACIONAL SOBRE OS SETE SABERES NECESSÁRIOS À EDUCAÇÃO DO PRESENTE, 2010, Fortaleza. Anais eletrônicos... Fortaleza: UNESCO/UECE/UCB, 2010. Disponível em: <http://www.

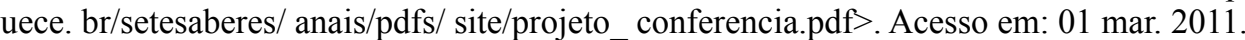


FREIRE, Paulo. Pedagogia da tolerância. São Paulo: UNESP, 2004.

Pedagogia da autonomia: saberes necessários à prática educativa. 30. ed. Rio de Janeiro: Paz e Terra, 1996.

LIRA, A. et al. Ensinar a compreensão: um dos saberes indispensáveis à educação do presente face às violências. In: CONFERÊNCIA INTERNACIONAL SOBRE OS SETE SABERES NECESSÁRIOS À EDUCAÇÃO DO PRESENTE, 2010, Fortaleza. Anais eletrônicos... Fortaleza, 2010. p. 1-7. Disponível em: <http://www.uece.br/ setesaberes/anais/trabalhos_autor.html>. Acesso em: 01 mar. 2012.

MARTINAZZO, C. J. A construção de conhecimentos pertinentes na educação escolar. In: CONFERÊNCIA INTERNACIONAL SOBRE OS SETE SABERES NECESSÁRIOS À EDUCAÇÃO DO PRESENTE, 2010, Fortaleza. Anais eletrônicos... Fortaleza, 2010a. p. 1-6. Disponível em: <http://www.uece.br/setesaberes/ anais/ trabalhos_autor.html>. Acesso em: 01 mar. 2012.

. Identidade humana: unidade e diversidade enquanto desafios para uma educação planetária. In: CONFERÊNCIA INTERNACIONAL SOBRE OS SETE SABERES NECESSÁRIOS À EDUCAÇÃO DO PRESENTE, 2010, Fortaleza. Anais eletrônicos... Fortaleza, 2010b. p. 1-7. Disponível em: <http://www.uece.br/ sete saberes/ anais/trabalhos_autor.html>. Acesso em: 01 mar. 2012.

MORIN, E. Os sete saberes necessários à educação do futuro. Tradução de Catarina Eleonora F. da Silva e Jeanne Sawaya. São Paulo: Cortez, 2003.

Introdução ao pensamento complexo. Porto Alegre: Sulina, 2005.

Meus filósofos. Tradução de Edgard Assis Carvalho e Mariza Perassi Bosco. Porto Alegre: Sulina, 2013.

PETRAGLIA, Izabel. Complexidade e auto-ética. Eccos Revista Científica, UNINOVE, São Paulo, v. 2, n. 1, p. 9-17, 2000.

SANTOS, Akiko. Complexidade e transdisciplinaridade em educação: cinco princípios para resgatar o elo perdido. Revista Brasileira de Educação, v. 13, n. 37, p. 71-83, jan./abr. 2008

VIEIRA, A. et al. Apurando as lentes e evitando miopias no contexto escolar. In: CONFERÊNCIA INTERNACIONAL SOBRE OS SETE SABERES NECESSÁRIOS À EDUCAÇÃO DO PRESENTE, 2010, Fortaleza. Anais eletrônicos... Fortaleza, 2010a, p. 1-8. Disponível em: <http://www.uece.br/setesaberes/anais/trabalhos_autor. html>. Acesso em: 01 mar. 2012.

Os sete saberes e o espaço escolar: contribuições para a aprendizagem e a formação do sujeito. . In: CONFERÊNCIA INTERNACIONAL SOBRE OS SETE SABERES NECESSÁRIOS À EDUCAÇÃO DO PRESENTE, 2010, Fortaleza. Anais eletrônicos... Fortaleza, 2010b, p. 1-7. Disponível em: <http://www.uece.br/setesaberes/ anais/trabalhos_autor.html>. Acesso em: 01 mar. 2012. 